\title{
Glomerular Filtration Rate Calculated by Modification of Diet in Renal Disease Formula Can be an Indicator of Impaired Glucose Tolerance and Diabetes in Coronary Artery Disease
}

\author{
Sinan Varol, Okay Abaci', Muhsin Kalyoncuoglu ${ }^{2}$, Vedat Sansoy ${ }^{1}$ \\ Department of Cardiology, Bagcilar Training and Research Hospital, Health Sciences University, 'Department of Cardiology, Institute of Cardiology, Istanbul University, \\ 2Department of Cardiology, Haseki Training and Research Hospital, Health Sciences University, Istanbul, Turkey
}

\section{Abstract}

Background: There is an increased risk for coronary artery disease (CAD) at modestly elevated levels of blood glucose which is still below the present threshold for type 2 diabetes mellitus (T2DM). In the present study, we aimed to define impaired glucose tolerance (IGT) and T2DM in patients with stable CAD and observe the relationship between clinical and laboratory findings. Materials and Methods: A total of 132 patients who had stable CAD and who had not been diagnosed as glucose intolerance or diabetes were enrolled. In one of the groups, there were patients with IGT or T2DM results and the other one consisted of patients with normal oral glucose tolerance test (OGTT) results. The Homeostasis Model Assessment of Insulin Resistance (HOMA-IR) was investigated in patients with fasting plasma glucose (FPG) $<100 \mathrm{mg} / \mathrm{dl}$. Results: The prevalance of IGT and T2DM was 30.3\%. In IGT + T2DM group, waist/hip ratio and creatinin level were significantly higher and estimated glomerular filtration rate (eGFR) was low. Only eGFR calculated by Modification of Diet in Renal Disease (MDRD) formula was a reliable parameter. MDRD eGFR $\leq 70 \mathrm{ml} / \mathrm{dk} / \mathrm{m}^{2}$ independently predicted IGT + T2DM diagnosis with 50\% sensitivity but with $82 \%$ specificity. Although it is insufficient to use it as an optimal screening test because of lower sensitivity, it can be a reliable indicator of IGT + DM in patients who had eGFR $\leq 70$. Insulin resistance was diagnosed in $29 \%$ of patients whose pretest values were FPG $<100 \mathrm{mg} / \mathrm{dl}$. Conclusion: MDRD eGFR can be an indicator for IGT + T2DM. OGTT irrespective of FPG level should be used to determine the presence of IGT + T2DM in stable CAD.

Keywords: Coronary artery disease, diabetes mellitus, estimated glomeruler filtration rate, glucose intolerance, Modification of Diet in Renal Disease

\section{INTRODUCTION}

Type 2 diabetes mellitus (T2DM) is a major risk factor for cardiovascular (CV) morbidity and mortality. ${ }^{[1]}$ There is an increased risk for coronary artery disease (CAD) at modestly elevated levels of blood glucose which is still below the threshold for T2DM. ${ }^{[2-5]}$ At diagnosis, there is one or more complication in more than half of the patients. CAD mortality is two times higher in patients with high glucose levels measured at the $2^{\text {nd }}$ hour. ${ }^{[6-8]}$

Impaired glucose tolerance (IGT), but not impaired fasting glucose (IFG), was determined as a risk factor for $\mathrm{CAD},{ }^{[7,9]}$ and it is related to $\mathrm{CV}$ and CAD mortality. ${ }^{[2,8,10-12]}$ Early diagnosis and treatment improves glucometabolic state, mortality, and morbidity. ${ }^{[13-16]}$

\begin{tabular}{|l|l|}
\hline \multicolumn{2}{|c|}{ Access this article online } \\
\hline Quick Response Code: & Website: \\
\hline & http://www.ijcva.com \\
\cline { 2 - 2 } & \\
\hline
\end{tabular}

\section{Materials and Methods}

A total of 132 patients were enrolled who had fasting plasma glucose (FPG) $<126 \mathrm{mg} / \mathrm{dl}$ and who had not been diagnosed as glucose intolerance (GI) or T2DM before and who had documented myocardial infarction (MI) and presence of coronary stenosis $>50 \%$ of the luminal diameter or documented coronary revascularization [Tables 1 and 2]. Patients with a history of acute coronary syndrome in 6 months were excluded

Address for correspondence: Dr. Sinan Varol, Department of Cardiology, Bagcilar Training and Research Hospital, Health Sciences University, Istanbul, Turkey. E-mail: sinanvarol@gmail.com

This is an open access journal, and articles are distributed under the terms of the Creative Commons Attribution-NonCommercial-ShareAlike 4.0 License, which allows others to remix, tweak, and build upon the work non-commercially, as long as appropriate credit is given and the new creations are licensed under the identical terms.

For reprints contact: reprints@medknow.com

How to cite this article: Varol S, Abaci O, Kalyoncuoglu M, Sansoy V. Glomerular filtration rate calculated by modification of diet in renal disease formula can be an indicator of impaired glucose tolerance and diabetes in coronary artery disease. Int J Cardiovasc Acad 2018;4:46-52. 


\begin{tabular}{|c|c|c|c|}
\hline & $n$ & Percentage & Mean \pm SD \\
\hline Age (years) & 132 & & $58 \pm 9$ \\
\hline \multicolumn{4}{|l|}{ Sex } \\
\hline Male & 115 & 87.1 & \\
\hline Female & 17 & 12.9 & \\
\hline \multicolumn{4}{|l|}{$\begin{array}{l}\text { Presence of cardiac risk } \\
\text { factors }\end{array}$} \\
\hline Hypertension & 104 & 78.8 & \\
\hline Dyslipidemia & 115 & 87.1 & \\
\hline \multicolumn{4}{|l|}{ Smoking status } \\
\hline Active & & 16.7 & \\
\hline Former & & 52.3 & \\
\hline Nonsmoker & & 31 & \\
\hline Waist circumference $(\mathrm{cm})$ & & & $100 \pm 7$ \\
\hline WHR & & & $0.97 \pm 0.04$ \\
\hline Height $(\mathrm{cm})$ & & & $1.68 \pm 8$ \\
\hline Weight (kg) & & & $82 \pm 13$ \\
\hline BMI & & & $29 \pm 3.8$ \\
\hline Creatinine (mg/dl) & & & $1 \pm 0.1$ \\
\hline MDRD GFR (ml/dk) & & & $80 \pm 16$ \\
\hline Cockroft GFR (ml/dk) & & & $93 \pm 25$ \\
\hline Duration of CAD (month) & & & $58 \pm 56$ \\
\hline \multicolumn{4}{|c|}{$\begin{array}{l}\text { Number of involved coronary } \\
\text { artery }\end{array}$} \\
\hline One vessel & & 28.6 & \\
\hline Two vessels & & 32.4 & \\
\hline Three vessels & & 28.6 & \\
\hline Unknown & & 10.4 & \\
\hline
\end{tabular}

\begin{tabular}{|c|c|c|c|}
\hline & $n$ & Percentage & Mean $\pm S D$ \\
\hline FPG (mg/dl) & & & $99 \pm 11$ \\
\hline $\mathrm{FPG}<100 \mathrm{mg} / \mathrm{dl}$ & 64 & 48.5 & \\
\hline FPG: $100-125 \mathrm{mg} / \mathrm{dl}$ & 68 & 51.5 & \\
\hline
\end{tabular}

SD: Standard deviation, FPG: Fasting plasma glucose

from the study. Oral glucose tolerance test (OGTT) was performed as it was defined by the World Health Organization. According to the procedure, patients were instructed not to limit carbohydrates 3 days before the procedure (daily $<150 \mathrm{mg} / \mathrm{dl}$ carbohydrates) and to perform daily physical activities. They were advised to give up eating and smoking after 10 PM the night before the test. $75 \mathrm{~g}$ glucose in $300 \mathrm{ml}$ water in $5 \mathrm{~min}$ was administered after giving the fasting blood sample. The blood sample was repeated at $120 \mathrm{~min}$.

In patients whose FPG level was $<100 \mathrm{mg} / \mathrm{dl}$, insulin levels were analyzed using the chemimmunesance method (IMMULITE 1000 system, Siemens GmbH, Germany). Homeostasis Model Assessment of Insulin Resistance (HOMA-IR) values were calculated via appropriate formulas. HOMA-IR $\geq 2.18$ was defined as the threshold for insulin resistance.
OGTT results were categorized based on the criteria which were defined by the American Diabetes Association Guidelines. $2^{\text {nd }}$ hour blood glucose $(2-\mathrm{h} \mathrm{BG})>200 \mathrm{mg} / \mathrm{dl}$ was diagnosed as T2DM. Levels within the range of 140-199/dl were classified as IGT. For the levels below the value of 140 $\mathrm{mg} / \mathrm{dl}$; IFG were diagnosed if $\mathrm{FPG} \geq 100 \mathrm{mg} / \mathrm{dl}$. Otherwise they were considered as normal test result.

IGT and T2DM patients were classified as one group and patients with normal result were classified as the control group. Patients who were diagnosed as IFG were excluded from the study. Waist circumference (WC); body mass index (BMI); estimated glomerular filtration rate (eGFR); and CAD severity assessed as one-, two-, or three-vessel disease; functional capacity, and Angina score were compared between the two groups. All patients were informed about the purpose of the study and OGTT test. Informed consent was obtained. All procedures and study design were approved by the local ethical committee.

\section{Statistical analysis}

Data from patients were assessed by SPSS v20 for Windows software (SPSS Inc, Chicago Ill, USA). Appropriate tests were used to decide the distribution of values in both the groups. $t$-test, one-way ANOVA, Mann-Whitney U-test, KruskalWallis test, and Chi-square test were used for comparisons. Risk factors were analyzed by the appropriate correlation analysis methods. Logistic regression analysis was used for obtaining independent predictors.

\section{RESULTS}

After the OGTT test, it was found that $65(49.2 \%)$ patients were normal, $27(20.5 \%)$ patients had IFG, 34 (25.8\%) patients had IGT, and $6(4.5 \%)$ patients had T2DM [Table 3]. Patients in both groups were young (control: $57 \pm 10$, IGT + T2DM: $61 \pm 9, P=0.095)$ and a male predominance was observed. Waist/hip ratio (WHR) was significantly higher in IGT + T2DM group (control: $0.96 \pm 0.04$ and IGT + T2DM: $0.98 \pm 0.04)$. Smoking status, presence and duration of hypertension, dyslipidemia, functional status and Angina class, history of MI, duration and severity of CAD, presence of MI, number of vessels revascularized, presence of coronary artery bypass graft, and drug usage were similar between the groups. The prevalence of IGT + T2DM was $30.3 \%$ in the whole population. Table $4 \mathrm{a}$ and $\mathrm{b}$ summarizes the demographic and clinical characteristics of the study cohort.

Logistic regression analysis showed that Modification of Diet in Renal Disease (MDRD) eGFR predicted the presence of IGT or T2DM. Age, sex, WHR, WC, BMI, and beta-blocker usage had no predictive values. After receiver operating characteristic (ROC) curve analysis, MDRD eGFR $\leq 70 \mathrm{ml} / \mathrm{min} / \mathrm{m}^{2}$ significantly predicted the presence of IGT or T2DM with $50 \%$ sensitivity and $82 \%$ specificity [Figure 1].

Insulin levels in patients with normal OGTT results were determined with respect to 0-h FPG levels. Based on the 


\begin{tabular}{|c|c|c|c|c|c|c|}
\hline & \multicolumn{2}{|c|}{$\mathrm{FPG}<100 \mathrm{mg} / \mathrm{dl}$} & \multicolumn{2}{|c|}{$\mathrm{FPG} \geq 100 \mathrm{mg} / \mathrm{dl}$} & \multicolumn{2}{|c|}{ Total } \\
\hline & $n$ & Percentage & $n$ & Percentage & $n$ & Percentage \\
\hline \multicolumn{7}{|c|}{ OGTT result } \\
\hline Normal & 43 & 32.6 & 22 & 16.6 & 65 & 49.2 \\
\hline IFG & 10 & 7.6 & 17 & 12.9 & 27 & 20.5 \\
\hline IGT & 10 & 7.6 & 24 & 18.2 & 34 & 25.8 \\
\hline DM & 1 & 0.8 & 5 & 3.7 & 6 & 4.5 \\
\hline Total & 64 & & 68 & & 132 & \\
\hline
\end{tabular}

IFG: Impaired fasting glucose, IGT: Impaired glucose tolerance, DM: Diabetes mellitus, OGTT: Oral glucose tolerance test, FPG: Fasting plasma glucose

\section{Table 4a: Demographic and clinical characteristics of the study cohort}

\begin{tabular}{|c|c|c|c|c|c|}
\hline & \multicolumn{2}{|c|}{ Normal $(n=65)$} & \multicolumn{2}{|c|}{ IGT + DM $(n=40)$} & \multirow[t]{2}{*}{$P$} \\
\hline & Percentage & Mean $\pm S D$ & Percentage & Mean \pm SD & \\
\hline Age & & $57 \pm 10$ & & $61 \pm 9$ & 0.095 \\
\hline \multicolumn{6}{|l|}{ Sex } \\
\hline Male & $88(n=57)$ & & $88(n=35)$ & & \\
\hline Female & $12(n=8)$ & & $12(n=5)$ & & \\
\hline Waist circumference $(\mathrm{cm})$ & & $99 \pm 8$ & & $102 \pm 6$ & 0.107 \\
\hline WHR & & $0.96 \pm 0.04$ & & $0.98 \pm 0.04$ & 0.019 \\
\hline Weight $(\mathrm{kg})$ & & $82 \pm 13$ & & $84 \pm 12$ & 0.477 \\
\hline BMI & & $28.8 \pm 3.9$ & & $29.7 \pm 3.7$ & 0.226 \\
\hline BUN (mg/dl) & & $16 \pm 5$ & & $16 \pm 4$ & 0.167 \\
\hline Creatinine (mg/dl) & & $0.9 \pm 0.16$ & & $1.0 \pm 0.17$ & 0.003 \\
\hline Cockroft GFR (cc/min) & & $97 \pm 27$ & & $86 \pm 21$ & 0.03 \\
\hline MDRD GFR (cc/min) & & $85 \pm 19$ & & $74 \pm 13$ & 0.002 \\
\hline $\mathrm{EF} \%$ & & $48 \pm 9$ & & $44 \pm 14$ & 0.184 \\
\hline CAD duration (month) & & $56 \pm 55$ & & $68 \pm 63$ & 0.319 \\
\hline HT presence & 72 & & 87 & & 0.068 \\
\hline HT duration (month) & & $47 \pm 55$ & & $70 \pm 73$ & 0.110 \\
\hline HL presence & 91 & & 85 & & 0.367 \\
\hline HL duration (month) & & $45 \pm 49$ & & $66 \pm 75$ & 0.479 \\
\hline \multicolumn{6}{|l|}{ Smoking status } \\
\hline Active & & 27 & 11 & & $>0.05$ \\
\hline Former & & 53 & 63 & & $>0.05$ \\
\hline Nonsmoker & & 20 & 26 & & $>0.05$ \\
\hline Smoking duration & & $27 \pm 22$ & & $27 \pm 26$ & $>0.05$ \\
\hline \multicolumn{6}{|l|}{ NYHA class } \\
\hline NYHA I & 94 & & 85 & & $>0.05$ \\
\hline NYHA II & 9 & & 15 & & $>0.05$ \\
\hline NYHA III & 0 & & 0 & & $>0.05$ \\
\hline NYHA IV & 0 & & 0 & & $>0.05$ \\
\hline \multicolumn{6}{|l|}{ CCS class } \\
\hline No angina & 80 & & 82 & & $>0.05$ \\
\hline CCS I & 5 & & 0 & & $>0.05$ \\
\hline CCS II & 15 & & 15 & & $>0.05$ \\
\hline CCS III & 0 & & 3 & & $>0.05$ \\
\hline CCS IV & 0 & & 0 & & $>0.05$ \\
\hline \multicolumn{6}{|l|}{ MI presence } \\
\hline None & 14 & & 15 & & $>0.05$ \\
\hline Subendocardial & 12 & & 5 & & $>0.05$ \\
\hline Nonanterior & 26 & & 35 & & $>0.05$ \\
\hline Anterior & 39 & & 30 & & $>0.05$ \\
\hline Unknown & 9 & & 15 & & - \\
\hline
\end{tabular}

IGT: Impaired glucose tolerance, DM: Diabetes mellitus, SD: Standard deviation, WHR: Waist/hip ratio, BMI: Body mass index, MDRD: Modification of Diet in Renal Disease, GFR: Glomerular filtration rate, BUN: Blood urea nitrogen, NYHA: New York Heart Association, CCS: Canadian Cardiovascular Society 
results, HOMA-IR values were calculated. Patients with insulin resistance were compared to others. Hypertension prevalence, BMI, and WHR were significantly higher in the insulin resistance group. The other parameters which showed significant differences are listed in Table 4. IGT + T2DM prevalence was similar between the two groups. Nearly $29 \%$ of patients who had normal OGTT results were found to have insulin resistance [Table 5].

\section{Discussion}

It was known that the presence of GI increases CAD mortality independent of developing T2DM. ${ }^{[17-19]}$ It is also important because of the increasing CAD risk factors ${ }^{[6,20]}$ and the development of coronary slow flow. ${ }^{[21]}$ Furthermore, it was found that negative effects on reperfusion in acute coronary events increased mortality due to heart failure and cardiogenic shock. ${ }^{[22]}$ Many clinical trials showed that increased CV risk was more associated with postprandial glucose levels than FPG. Hence, IGT patients have more CV risks compared to patients who have IFG..$^{[7,23]}$ Early diagnosis is important because it was demonstrated that the risk of acute cardiac event and T2DM development was lowered with lifestyle modifications ${ }^{\text {[24-27] }}$ and pharmacological therapy with metformin, acarbose, and rosiglitazone. ${ }^{[25,28]}$

In patients with IFG, $\mathrm{CV}$ risk increase and risk reduction by treatment were controversial. ${ }^{[23]}$ Hence, we compared

\begin{tabular}{|c|c|c|c|c|c|}
\hline \multirow[t]{2}{*}{ Parameter } & \multicolumn{2}{|c|}{ Normal $(n=65)$} & \multicolumn{2}{|c|}{ IGT + DM $(n=40)$} & \multirow[t]{2}{*}{$P$} \\
\hline & Mean \pm SD & Percentage & Mean \pm SD & Percentage & \\
\hline \multicolumn{6}{|l|}{ Number of involved coronary artery } \\
\hline One vessel & & 31 & & 25 & $>0.05$ \\
\hline Two vessels & & 35 & & 28 & $>0.05$ \\
\hline Three vessels & & 29 & & 27 & $>0.05$ \\
\hline Unknown & & 5 & & 20 & - \\
\hline \multicolumn{6}{|l|}{ Number of revascularized vessel } \\
\hline None & & 3 & & 15 & $>0.05$ \\
\hline One vessel & & 58 & & 55 & $>0.05$ \\
\hline Two vessels & & 25 & & 15 & $>0.05$ \\
\hline Three vessels & & 11 & & 5 & $>0.05$ \\
\hline Unknown & & 3 & & 10 & - \\
\hline \multicolumn{6}{|l|}{ CABG presence } \\
\hline None & & 85 & & 78 & $>0.05$ \\
\hline Positive & & 15 & & 22 & $>0.05$ \\
\hline Family history of CAD & & 55 & & 50 & $>0.05$ \\
\hline Family history of premature CAD & & 21 & & 21 & $>0.05$ \\
\hline Family history of DM & & 19 & & 31 & $>0.05$ \\
\hline \multicolumn{6}{|l|}{ Duration of drug usage (month) (\%) } \\
\hline ACE inhibitor & $31 \pm 48$ & 54 & $54 \pm 61$ & 72 & $>0.05$ \\
\hline ARB & $14 \pm 33$ & 23 & $11 \pm 28$ & 16 & $>0.05$ \\
\hline Beta-blocker & $38 \pm 47$ & 81 & $49 \pm 55$ & 75 & $>0.05$ \\
\hline Calcium channel blocker & $11 \pm 28$ & 17 & $11 \pm 27$ & 22 & $>0.05$ \\
\hline Statin & $40 \pm 45$ & 90 & $50 \pm 57$ & 75 & $>0.05$ \\
\hline
\end{tabular}

ARB: Angiotensin receptor blocker, ACE: Angiotensin-converting enzyme, CABG: Coronary artery bypass graft, CAD: Coronary artery disease,

DM: Diabetes mellitus, IGT: Impaired glucose tolerance

Table 5: Comparison of groups according to Homeostasis Model Assessment of Insulin Resistance value

\begin{tabular}{|c|c|c|c|c|c|}
\hline & \multicolumn{2}{|c|}{ HOMA-IR $<2.18(n=54)$} & \multicolumn{2}{|c|}{ HOMA-IR $\geq 2.18(n=22)$} & \multirow[t]{2}{*}{$P$} \\
\hline & Percentage & Mean \pm SD & Percentage & Mean \pm SD & \\
\hline Duration of HT (months) & & $45 \pm 54$ & & $78 \pm 68$ & 0.013 \\
\hline Waist circumference $(\mathrm{cm})$ & & $98 \pm 7$ & & $105 \pm 6$ & 0.0001 \\
\hline WHR (cm) & & $0.97 \pm 0.04$ & & $0.98 \pm 0.05$ & 0.332 \\
\hline Weight $(\mathrm{kg})$ & & $78 \pm 10$ & & $90 \pm 15$ & 0.0001 \\
\hline BMI & & $27.6 \pm 3.0$ & & $31.8 \pm 4.3$ & 0.0001 \\
\hline IGT + T2DM prevalence & 15 & & 23 & & 0.327 \\
\hline Patients with FPG $<100 \mathrm{mg} / \mathrm{dl}$ & 71 & & 29 & & - \\
\hline
\end{tabular}

HOMA-IR: Homeostasis Model Assessment of Insulin Resistance, SD: Standard deviation, BMI: Body mass index, T2DM: Type 2 Diabetes Mellitus, IGT: Impaired Glucose Tolerance, FPG: Fasting plasma glucose, WHR: Waist/hip ratio, SD: Standard deviation 
IGT + T2DM group with patients with normal results. In our study, IGT was $25.8 \%$ and T2DM was $4.5 \%$. Large-scale studies such as Euro Heart Survey (EHS), China Heart Survey (CHS) and GAMI study were conducted for revealing GI in CAD patients. ${ }^{[29-31]}$ They concluded higher prevalance of GI and diabetes [Figure 2]. Taubert et al. demonstrated that new onset of T2DM was $32 \%$ in patients who had been directed to elective angiography. ${ }^{[32]}$ EHS, CHS, and GAMI were conducted in patients who had been asked for angiography. However, our study involved patients who were on routine follow-up program. These patients had stable CAD levels with low New York Heart Association (NYHA) and Canadian Cardiovascular Society (CCS) class. This could be a reason of lower prevalance of IGT and T2DM. On the other hand, the duration of CAD was 56 months in the normal group and 68 months in IGT and T2DM groups. It could be possible that IGT or T2DM development had been detected in these patients

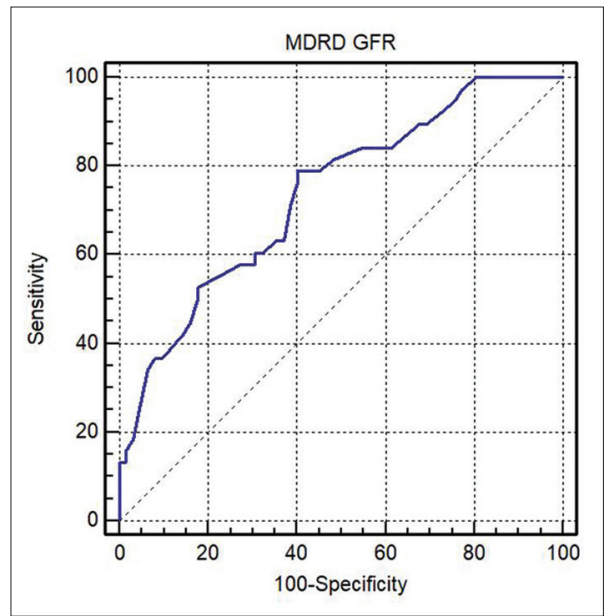

Figure 1: Receiver-operating characteristic curve of Modification of Diet in Renal Disease glomerular filtration rate exhibits the specific threshold value as $\leq 70 \mathrm{ml} / \mathrm{min} / \mathrm{m}^{2}$ for maximized predictive value for the presence of impaired glucose tolerance or diabetes mellitus with $50 \%$ sensitivity and $82 \%$ specificity (area under the curve: 0.736 ; 95\% confidential interval: 0.639-0.819) and they were already diagnosed as GI and diabetes. As a result, lower incidence was found in the rest of the patients. However, patients were younger in our study (mean age in our study: $58 \pm 9$, EHS: $66 \pm 9$, and CHS: $68 \pm 9$ years).

Age and sex were similar between the groups. Although Gunner et al. observed that BMI $>30 \mathrm{~kg} / \mathrm{m}^{2}$ was a positive predictive value, ${ }^{[32]}$ patients in our study had high values of WC and BMI, which did not differ between the groups. However, in patients with insulin resistance, these two parameters were significantly high compared to those who did not have it. It seems that it can be transformed into GI in the future as had been expected. IGT + T2DM group had significantly higher WHR. Moreover, logistic regression analysis displayed that WHR could be predictive. Renal function parameters were more deteriorated in the IGT + T2DM group. It could be interpreted as the effect of impaired glucose control. It is known that microalbuminuria is related to GI. ${ }^{[33]}$ Stages of nephropathy in diabetic patients were defined as normoalbuminuria, microalbuminuria, macroalbuminuria, and reduced GFR. ${ }^{[34]}$ The occurrence of an isolated reduction in GFR without antecedent microalbuminuria in patients with biopsy-proven diabetic kidney disease was also documented. ${ }^{[35]}$ Another study confirmed this finding with the absence of albuminuria and retinopathy. ${ }^{[36]}$ This finding confirms the presence of nonalbuminuric alternate pathway. ${ }^{[34]}$ A large-scale study confirmed lower eGFR values even in newly diagnosed prediabetic patients. ${ }^{[37]}$ Lower GFR is also found to be associated with insulin resistance. ${ }^{[38,39]}$

In logistic regression analysis, only MDRD eGFR was an independent predictor of IGT + T2DM. ROC analysis showed that MDRD eGFR $\leq 70 \mathrm{ml} / \mathrm{min} / \mathrm{m}^{2}$ criteria had $50 \%$ sensitivity, but $82 \%$ specificity for predicting IGT + T2DM. It is not suitable for screening test, but low eGFR values could indicate the presence of IGT + T2DM. Hence, these patients should be directed to take the OGTT test.

The relationship between insulin resistance and increased CV mortality has already been demonstrated. ${ }^{[40-43]}$ In CAD patients,

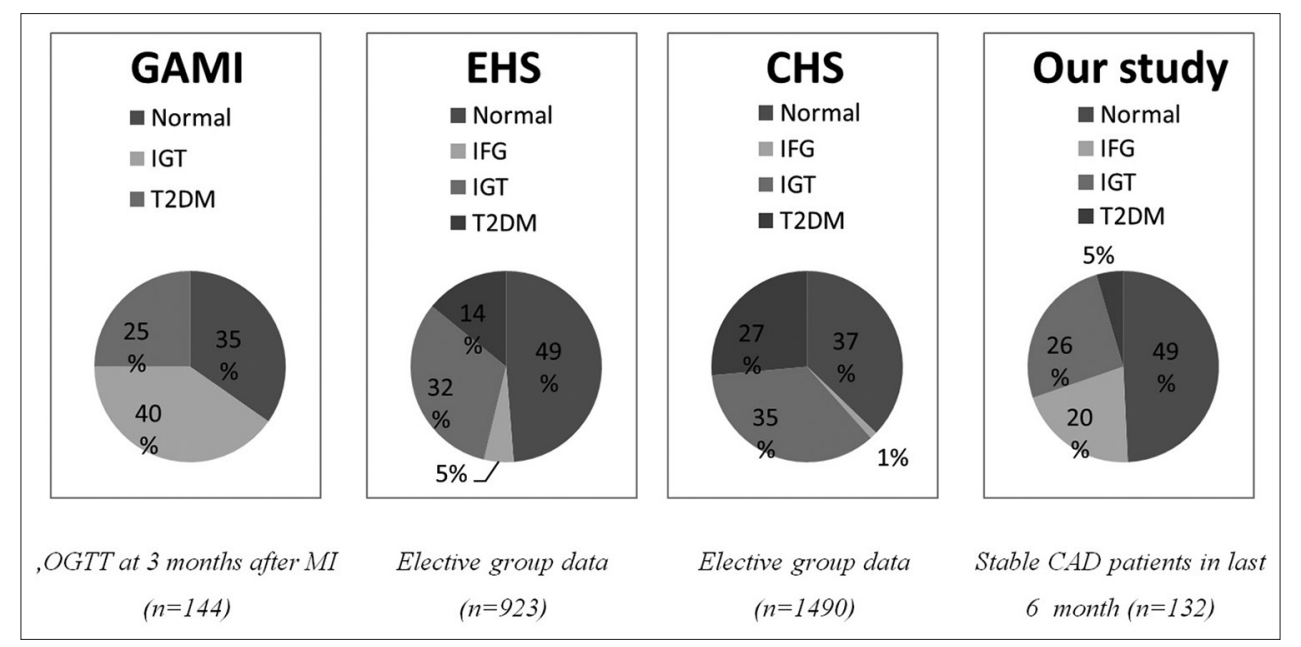

Figure 2: GAMI: Glucose tolerance in patients with acute myocardial infarction Study, EHS: Euro Heart Survey, CHS: China Heart Survey 
insulin resistance prevalence is common (s41), and there is a significant relationship between and Gensini score. ${ }^{[44]}$ In our study, 76 patients who had FPG $<100 \mathrm{mg} / \mathrm{dl}$ results underwent the measurement of insulin levels. HOMA-IR values were calculated. The prevalence of insulin resistance was $29 \%$. Weight, BMI, and WC were significantly higher in patients who had insulin resistance. There is no statistically significant difference between creatinine, Cockroft eGFR, and MDRD eGFR values. Nearly $27 \%$ of patients who had new-onset IGT or T2DM had FPG $<100 \mathrm{mg} / \mathrm{dl}$. This is one of the important results of our study. In EHS, Two-thirds of the patients would be undiagnosed if the OGTT test had not been performed. Similar results have been increasingly obtained in recent years. ${ }^{[0,29]}$

Our study was conducted on "functionally good" patients who planned to undergo coronary angiography. Serum creatinin values were between 0.6 and $1.4 \mathrm{mg} / \mathrm{dl}$. They had low CCS and NYHA class. Echocardiographic ejection fraction\% values were high. Perhaps, more strong relationships could be detected if they were older or had severe renal dysfunction. Nevertheless, the presence of a significant relationship between eGFR and IGT + DM status is a good finding. Nevertheless, further large-scale studies are needed to confirm this result.

\section{Conclusion}

GI and T2DM in CAD patients are common. Conventional cardiac risk factors, drug use, $\mathrm{WC}$ and $\mathrm{BMI}$, and CAD duration and severity could not predict IGT + T2DM. Only MDRD eGFR was found to be an independent predictor. Insulin resistance calculated as HOMA-IR was high. OGTT should be performed irrespective of FPG.

\section{Financial support and sponsorship}

Nil.

\section{Conflicts of interest}

There are no conflicts of interest.

\section{RefEREnCES}

1. Haffner SM, Lehto S, Rönnemaa T, Pyörälä K, Laakso M. Mortality from coronary heart disease in subjects with type 2 diabetes and in nondiabetic subjects with and without prior myocardial infarction. N Engl J Med 1998;339:229-34.

2. International Diabetes Federation Guideline Development Group. Global guideline for type 2 diabetes. Diabetes Res Clin Pract 2014;104:1-52.

3. Coutinho M, Gerstein HC, Wang Y, Yusuf S. The relationship between glucose and incident cardiovascular events. A metaregression analysis of published data from 20 studies of 95,783 individuals followed for 12.4 years. Diabetes Care 1999;22:233-40.

4. Khaw KT, Wareham N, Luben R, Bingham S, Oakes S, Welch A, et al. Glycated haemoglobin, diabetes, and mortality in men in norfolk cohort of European prospective investigation of cancer and nutrition (EPIC-Norfolk). BMJ 2001;322:15-8.

5. DECODE Study Group, European Diabetes Epidemiology Group. Is the current definition for diabetes relevant to mortality risk from all causes and cardiovascular and noncardiovascular diseases? Diabetes Care 2003;26:688-96.

6. Fontbonne A, Eschwège E, Cambien F, Richard JL, Ducimetière P, Thibult $\mathrm{N}$, et al. Hypertriglyceridaemia as a risk factor of coronary heart disease mortality in subjects with impaired glucose tolerance or diabetes. Results from the 11-year follow-up of the Paris prospective study. Diabetologia 1989;32:300-4.

7. Fuller JH, Shipley MJ, Rose G, Jarrett RJ, Keen H. Coronary-heart-disease risk and impaired glucose tolerance. The Whitehall study. Lancet 1980;1:1373-6.

8. Lowe LP, Liu K, Greenland P, Metzger BE, Dyer AR, Stamler J, et al. Diabetes, asymptomatic hyperglycemia, and 22-year mortality in black and white men. The Chicago Heart Association detection project in industry study. Diabetes Care 1997;20:163-9.

9. Arbel Y, Zlotnik M, Halkin A, Havakuk O, Berliner S, Herz I, et al. Admission glucose, fasting glucose, HbAlc levels and the SYNTAX score in non-diabetic patients undergoing coronary angiography. Clin Res Cardiol 2014;103:223-7.

10. Tominaga M, Eguchi H, Manaka H, Igarashi K, Kato T, Sekikawa A, et al. Impaired glucose tolerance is a risk factor for cardiovascular disease, but not impaired fasting glucose. The funagata diabetes study. Diabetes Care 1999;22:920-4.

11. Fisher M. Diabetes and atherogenesis. Heart 2004;90:336-40.

12. George A, Bhatia RT, Buchanan GL, Whiteside A, Moisey RS, Beer SF, et al. Impaired glucose tolerance or newly diagnosed diabetes mellitus diagnosed during admission adversely affects prognosis after myocardial infarction: An observational study. PLoS One 2015;10:e142045.

13. Marwick TH. Diabetic heart disease. Heart 2006;92:296-300.

14. Karakoç A. Diabetic nephropathy and its treatment. Turk Klinikleri J Endocrin Spec Topics 2008;1:1-11.

15. Chen Y, Wang J, An Y, Gong Q, He Y, Zhang B, et al. Effect of lifestyle interventions on reduction of cardiovascular disease events and its mortality in pre-diabetic patients: Long-term follow-up of da Qing diabetes prevention study. Zhonghua Nei Ke Za Zhi 2015;54:13-7.

16. Chiasson JL, Josse RG, Gomis R, Hanefeld M, Karasik A, Laakso M, et al. Acarbose treatment and the risk of cardiovascular disease and hypertension in patients with impaired glucose tolerance: The STOP-NIDDM trial. JAMA 2003;290:486-94.

17. Uçar Ö, Aydoğdu S. Diabetes mellitus and cardiovascular system. Turk Klinikleri J Int Med Sci 2007;3:1-7.

18. Dursunoglu D, Evrengul H, Kaftan A, Kılıç M, Sermez Y. Coronary atherosclerosis and diabetes. Turk Klinikleri J Cardiol 2004;17:55-60.

19. Fujihara K, Igarashi R, Yamamoto M, Ishizawa M, Matsubayasi Y, Matsunaga S, et al. Impact of glucose tolerance status on the development of coronary artery disease among working-age men. Diabetes Metab 2017;43:261-4.

20. Simons LA, Simons J, Friedlander Y, McCallum J. Usefulness of fasting plasma glucose to predict mortality or coronary heart disease in persons $>=60$ years of age without diabetes mellitus or in those with undiagnosed diabetes mellitus (from the dubbo study). Am J Cardiol 2008;102:831-4.

21. Binak E, Gunduz H, Sahin M, Kurtoglu N, Dindar I. The relation between impaired glucose tolerance and slow coronary flow. Int J Cardiol 2006;111:142-6.

22. Fefer P, Hod H, Ilany J, Shechter M, Segev A, Novikov I, et al. Comparison of myocardial reperfusion in patients with fasting blood glucose $<$ or $=100,101$ to 125 , and $>125 \mathrm{mg} / \mathrm{dl}$ and ST-elevation myocardial infarction with percutaneous coronary intervention. Am J Cardiol 2008;102:1457-62.

23. Blake DR, Meigs JB, Muller DC, Najjar SS, Andres R, Nathan DM, et al. Impaired glucose tolerance, but not impaired fasting glucose, is associated with increased levels of coronary heart disease risk factors: Results from the baltimore longitudinal study on aging. Diabetes 2004;53:2095-100.

24. Harris MI, Flegal KM, Cowie CC, Eberhardt MS, Goldstein DE, Little RR, et al. Prevalence of diabetes, impaired fasting glucose, and impaired glucose tolerance in U.S. adults. The Third National Health and Nutrition Examination Survey, 1988-1994. Diabetes Care 1998;21:518-24.

25. Knowler WC, Barrett-Connor E, Fowler SE, Hamman RF, Lachin JM, Walker EA, et al. Reduction in the incidence of type 2 diabetes with lifestyle intervention or metformin. N Engl J Med 2002;346:393-403.

26. Eriksson KF, Lindgärde F. Prevention of type 2 (non-insulin-dependent) diabetes mellitus by diet and physical exercise. The 6-year Malmö feasibility study. Diabetologia 1991;34:891-8. 
27. Tuomilehto J, Lindström J, Eriksson JG, Valle TT, Hämäläinen $H$, Ilanne-Parikka P, et al. Prevention of type 2 diabetes mellitus by changes in lifestyle among subjects with impaired glucose tolerance. $\mathrm{N}$ Engl J Med 2001;344:1343-50.

28. American Diabetes Association and National Institute of Diabetes, Digestive and Kidney Diseases. The prevention or delay of type 2 diabetes. Diabetes Care 2002;25:742-9.

29. Bartnik M, Rydén L, Ferrari R, Malmberg K, Pyörälä K, Simoons M, et al. The prevalence of abnormal glucose regulation in patients with coronary artery disease across Europe. The Euro Heart Survey on diabetes and the heart. Eur Heart J 2004;25:1880-90.

30. Hu DY, Pan CY, Yu JM; China Heart Survey Group. The relationship between coronary artery disease and abnormal glucose regulation in China: The China Heart Survey. Eur Heart J 2006;27:2573-9.

31. Norhammar A, Tenerz A, Nilsson G, Hamsten A, Efendíc S, Rydén L, et al. Glucose metabolism in patients with acute myocardial infarction and no previous diagnosis of diabetes mellitus: A prospective study. Lancet 2002:359:2140-4.

32. Taubert G, Winkelmann BR, Schleiffer T, März W, Winkler R, Gök R, et al. Prevalence, predictors, and consequences of unrecognized diabetes mellitus in 3266 patients scheduled for coronary angiography. Am Heart J 2003;145:285-91.

33. Atkins RC. The epidemiology of chronic kidney disease. Kidney Int Suppl 2005;(94):S14-8.

34. Reutens AT, Atkins RC. Epidemiology of diabetic nephropathy. Contrib Nephrol 2011;170:1-7.

35. Lane PH, Steffes MW, Mauer SM. Glomerular structure in IDDM women with low glomerular filtration rate and normal urinary albumin excretion. Diabetes 1992;41:581-6.

36. Kramer HJ, Nguyen QD, Curhan G, Hsu CY. Renal insufficiency in the absence of albuminuria and retinopathy among adults with type 2 diabetes mellitus. JAMA 2003;289:3273-7.

37. Plantinga LC, Crews DC, Coresh J, Miller ER $3^{\text {rd }}$, Saran R, Yee J, et al. Prevalence of chronic kidney disease in US adults with undiagnosed diabetes or prediabetes. Clin J Am Soc Nephrol 2010;5:673-82.

38. Pham H, Robinson-Cohen C, Biggs ML, Ix JH, Mukamal KJ, Fried LF, et al. Chronic kidney disease, insulin resistance, and incident diabetes in older adults. Clin J Am Soc Nephrol 2012;7:588-94.

39. Nerpin E, Risérus U, Ingelsson E, Sundström J, Jobs M, Larsson A, et al. Insulin sensitivity measured with euglycemic clamp is independently associated with glomerular filtration rate in a community-based cohort. Diabetes Care 2008;31:1550-5.

40. Haffner SM, D’Agostino R Jr., Mykkänen L, Tracy R, Howard B, Rewers $\mathrm{M}$, et al. Insulin sensitivity in subjects with type 2 diabetes. Relationship to cardiovascular risk factors: The insulin resistance atherosclerosis study. Diabetes Care 1999;22:562-8.

41. Swan JW, Anker SD, Walton C, Godsland IF, Clark AL, Leyva F, et al. Insulin resistance in chronic heart failure: Relation to severity and etiology of heart failure. J Am Coll Cardiol 1997;30:527-32.

42. Iozzo P, Chareonthaitawee P, Dutka D, Betteridge DJ, Ferrannini E, Camici PG, et al. Independent association of type 2 diabetes and coronary artery disease with myocardial insulin resistance. Diabetes 2002;51:3020-4

43. Deveci E, Yesil M, Akinci B, Yesil S, Postaci N, Arikan E, et al. Evaluation of insulin resistance in normoglycemic patients with coronary artery disease. Clin Cardiol 2009;32:32-6.

44. Nurkalem Z, Hasdemir H, Ergelen M, Aksu H, Sahin I, Erer B, et al. The relationship between glucose tolerance and severity of coronary artery disease using the gensini score. Angiology 2010;61:751-5. 